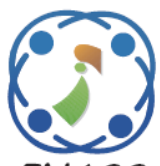

\title{
Hybrid FLC-LMS Algorithm for Predicting Sediment Volume in the River
}

\author{
Sri Arttini Dwi Prasetyowati ${ }^{1 *} \quad$ Bustanul Arifin $^{1} \quad$ Junido Ardalli ${ }^{1}$ \\ Munaf Ismail $^{1} \quad$ Imam Much Ibnu Subroto ${ }^{1} \quad$ Mauridhi Hery Purnomo $^{2 *}$ \\ ${ }^{1}$ Universitas Islam Sultan Agung Semarang, Indonesia \\ ${ }^{2}$ Institut Teknologi Sepuluh Nopember Surabaya, Indonesia \\ * Corresponding author's Email: arttini@unissula.ac.id and hery@ee.its.ac.id
}

\begin{abstract}
Problems such as flooding, various diseases from microbial pathogens, rivers becoming slum and unsightly, reduced availability: The data found that $82 \%$ of the 550 rivers in Indonesia were polluted and in critical condition. The high level of pollution caused various of clean water and many more. Sediment was one of the causes of that problem. There have been many studies detecting objects in the water, but no one predicted the volume of objects in the water. The purpose of this research is to make a device to detect the volume of sediment in the rivers to improve the performance of river monitoring. A device was equipped with an infrared sensor. Raising and lowering the sensor under the device was controlled by the front DC motor with a Fuzzy Logic Controller (FLC) algorithm using two input and one output. Error (E) and change of error (CE) were inputs for FLC and change of control was the output. The fuzzy membership function depended on the distance of the sensor to the sediment. The number of membership functions used was less than the previous research, so the calculation was much simple. This research used hybrid FLC and Adaptive LMS predictive algorithm. Fuzzy Logic Controller was for controlling the Front DC motor when raising and lowering the sensor and Adaptive LMS predictive algorithm was for predicting the volume and minimalizing the error calculation. PID control was also used as a comparison. The results showed that using the FLC algorithm can find sediment in less than four seconds with an error rate of 0.0005, while the PID sensor found sediment in more than 4 seconds with an error rate of 0.001. In addition, the Adaptive LMS predictive algorithm minimized the error calculation with an accuracy level of 99.66 percent.
\end{abstract}

Keywords: Sediment, Infrared sensor, DC motor, Fuzzy logic controller, Adaptive least mean square.

\section{Introduction}

Sediment causes a very serious water problems including flooding, water pollution, and other problems related to water sediment. The data found that $82 \%$ of the 550 rivers in Indonesia were polluted and in critical condition [1]. Hence, river maintenance is very important especially for monitoring the existence of river sediment. The aim of this research is to make a prototype to help maintaining river conditions. Nowadays, current river conditions have a lot of sediment, which makes the river shallow and affects the volume of water that can be accommodated. Due to the large number of rivers in Indonesia, the river detection cannot only be done by human labor. Therefore, it is inevitable to create a smart device needed to detect sediment and measure its volume automatically so that any potential hazards can be detected early. This research developed a device of a small boat using an infrared sensor for monitoring the river. The Fuzzy Logic Controller (FLC) was designed to control the Front DC motor to raise and lower the sensor. The FLC provided an accurate controller for controlling the systems compared to the classical controllers such as a PID controller [2]. The following literature has been published about sensors, motor, and methods for detecting objects in the water.

A study explained that Fuzzy Logic Controller was an accurate controller for controlling the systems when compared to the classical controllers, such as a Proportional-Integral-Derivative (PID) controller. The fuzzy logic controller (FLC) was designed to 
control the position of a DC motor. The motor model was developed and transformed in a subsystem by using the Matlab/Simulink and its parameters were taken from a datasheet for a real motor [2].

An article declared an algorithm that is suitable for all sonar detection applications as well as for all sonar types for detecting objects in the water. The algorithm do not require any knowledge about the shape and the size of the target [3].

A study of an adaptive control for the DC motor using meta-heuristic algorithms explained the simulation results that proposed adaptive control strategies as a viable alternative to regulate the speed of the motor subject to different operation scenarios. The comparative analysis with a robust control approach revealed the advantages of the adaptive strategy based on the meta-heuristic techniques in the velocity regulation of the DC motor [4].

An Overview of the Next-Generation Underwater Target Detection and Tracking: An Integrated Underwater Architecture provided a comprehensive survey of unmanned underwater vehicles and different ray tracing models. These were essential in target detection and tracking to answer several questions regarding the current necessities of underwater networks. Finally, it provides a solution that opens several doors for community research to excel in this area. [5].

Another research was using a genetic algorithmoptimized the fuzzy proportional-integral-derivative controller. It showed that the genetic algorithm based proportional-integral-derivative, the type fuzzy logic controller, has a superior performance than the conventional proportional-integral-derivative controller, gain tuned proportional-integralderivative controller, the conventional fuzzy proportional-integral-derivative controller, and scaling factor tuned the fuzzy proportional-integralderivative controller [6].

Soetjie Poernama Sari conducted a research using a local fishing boat that has been installed tow fish. Inside this tow fish, there were two sonars mounted on the side of the bottom. The sonar used was the CMax Side Scan Sonar which had a frequency between $100 \mathrm{kHz}$ to $500 \mathrm{kHz}$. However, the volume of the targets was not calculated [7].

Table 1. Previous research, the code "Y" means the research used the algorithm or calculated the volume, while the code " $\mathrm{N}$ " means the research did not use the algorithm or did not calculate the volume. What is very significant from the six studies above is that the previous research only focused on how to detect underwater targets, but did not calculate the volume. However, some previous research has become a reference for this research in terms of DC motor parameters and determining the best algorithm for DC motor control.

It can be seen that there are only two previous studies using FLC, number 1 (one) and number 5 (five). The number 1 (one) of previous research controlled the position using FLC, but used 7 (seven) membership functions for "Error" (E) and 5 (five) membership functions for "Change of Error" (CE). As for this research, this used 5 membership functions for both "Error" and "Change of Error".

The number 5 (five) of previous research used FLC and genetic algorithms (a hybrid between FLC and genetic algorithms) on the Brushless Direct Current (DC) motor to control its speed. Meanwhile, this paper examined DC motors (not brushless DC motors) using FLC and controlled the output using adaptive LMS (Hybrid FLC and adaptive LMS). The study that used Fuzzy Logic Method to develop prototype for reading the turbidity level of water and sent a real-time report was done, but that did not calculate the volume [8].

Other research that did not use FLC are described below.

This paper focuses on automated recognition of underwater objects by means of light detection and ranging (LIDAR) systems. Different from most works involved in underwater object recognition with LIDAR, where objects are recognized by their shape, here the interest is distinguishing objects on the basis of physical/chemical properties of object materials [9].

Another research about LIDAR presents a neural network architecture using a support vector machine (SVM) as an inference engine (IE) for classification of light detection and ranging (LIDAR) data. The data gives a sequence of laser backscatter intensities obtained from laser shots generated from an airborne object at various altitudes above the earth surface. LIDAR data is pre-filtered to remove high frequency noise [10].

The research that offers a new unsupervised statistically-based algorithm for the detection of underwater objects in synthetic aperture sonar (SAS) imagery due to its high-resolution imagery was realized. Its resolution is independent of the range [11].

Another research that conducted the experiments in an aquarium tank filled with water and a sediment layer was a study to investigate the performance and phenomenology of electrical impedance tomography for underwater applications. An evaluation is conducted of the ability to detect compact objects buried at various depths in the sediment, with different horizontal separations, and at various vertical separations between the electrode array and 
the sediment layer. The objects include metallic and nonmetallic mine-like objects and inert ammunition projectiles, all appropriately scaled down in size. The effects of a number of other physical factors are studied, including sediment type, water turbidity and salinity, and object coating integrity and rusting [12] This study presents various bathymetric filters, based on the well-known matched filter (MF), adaptive MF, and adaptive cosine/coherence estimator detectors, for underwater target detection from hyperspectral remote-sensing data [13].

The research using an autonomous underwater vehicle to track a coastal upwelling front was developed to autonomously detect and track an upwelling front. During the Controlled, Agile, and Novel Observing Network (CANON) experiment in April 2011, the Tethys long-range AUV ran the algorithm to autonomously track an upwelling front in a dynamic coastal upwelling region in Monterey Bay, CA. The AUV transected the upwelling front 14 times over two days, providing a very high-resolution depiction of the front [14].

The study for detect water quality was found. Two factors that directly affect the life quality in the XXI century cities are the water and air quality that can be monitored using the combination of low cost sensing modules, machine to machine (M2M) and internet of things (IoT) technologies. In this context, this study presents a wireless sensor network architecture that combines low cost sensing nodes and a low cost multi-parameters sensing probe for reliable monitoring of water quality parameters of surface waters (lakes, estuaries and rivers) in urban areas. A particular attention is dedicated to the design of the conductivity, temperature and turbidity signal conditioning circuits, highlighting important issues related to linearization, measuring dynamic range and low-cost implementation by using commercial offthe-shelf components and devices [15].

Furthermore, it shows the research that provide Fuzzy development. Fuzzy control, an intelligent control method, is generally employed to deal with complex nonlinear controlled objects that cannot be expressed by accurate mathematical model. Memristor, whose unique advantages are automatic successive memory and nonvolatility, brought new opportunity for solving the key question of fuzzy control. With the design idea of software harden, that was the research that constructed membership function in the fuzzy controller based on the unique feature of crossbar array of the spintronic memristor and elaborated the whole construction process [16]. Starting with looking for the river bed, the front DC motor raises or lowers the infrared sensor with the

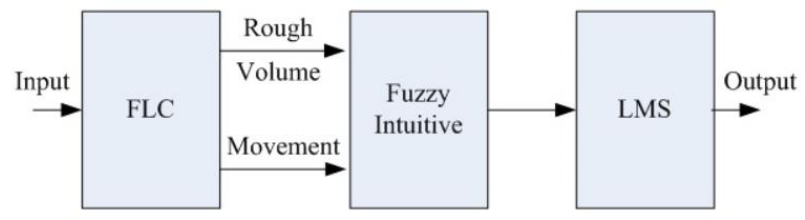

Figure. 1 Research schemes

FLC algorithm. Information from the sensor forwarded to the microprocessor, Arduino Mega 2560 is processed, then controls the side DC motor to move the device forward or rotating to calculate the length, width, and height of the sediment or control the front DC motor to raise and lower the sensor to detect object. The flowchart in determining the length, width, and height will be explained in detail using matrices. But before that, the flowchart of research methods would be explained in Fig. 1.

This study is proposed to develop prototype for predicting volume sediment in the river using hybrid FLC-LMS algorithm, with Fuzzy intuitive that played a role as the decision maker. The schematic in Fig. 1 shows how the Hybrid process was carried out. First, determine the river bed using FLC as a benchmark for measuring sediment height. Then FLC drove the prototype moved to calculate the length and width of the sediment. The length, width and height obtained were still contain errors so that the volume obtained was the rough volume. So, it will be examined whether it is necessary to improve these measurements by predicting the correct size or not. The Fuzzy Intuitive Sets would help to make the decision whether an Adaptive LMS process need to be done.

This scheme shows a new method, because it uses two algorithms at once, namely FLC and LMS. In addition, between the two algorithms, there was Fuzzy intuitive that played a role as the decision maker. Fuzzy intuitive has parameters that measure uncertainty and semantic information, which determine whether an Adaptive LMS process need to be done.

This paper is organized into several sections, as follows. Section 2 presents design of the electronic prototype. Section 3 presents how the FLC design to control front DC motor. The comparison between FLC and PID is presented in Section 4. Section 5 presents how to measure the length, height and width of the sediment after FLC drove the prototype moving. The Fuzzy Intuitive Sets for making decision to improve measurement results is presented in Section 6, followed by process predictive LMS adaptive for minimizing error measurement in Section 7. Section 8 presents scaling prototype to realize the actual device, and finally, the conclusions are summarized in Section 9. 


\section{Electronic prototype design}

Arduino Mega 2560, as a processor and controller, would be programmed through the Arduino IDE, with a push button located near the LCD to make it easy for setting up or testing the prototype. A lipo socket is where the lipo battery is connected. A header pin is used to link the lipo battery source to the electronic part of the motor driver and the Arduino Mega 2560.

An adjustable infrared sensor detects objects in the water at a certain distance. It will be " 0 " or "LOW" if it detects solid objects and becomes "1" or "HIGH" if it does not detect the existence of objects in the water. Fig. 2 shows the electrical circuits and Fig. 3 shows the block diagrams of the prototype.

Seven programs would run the prototype: An LCD and button program, a front motor program, a front DC motor program, rotary encoder program, side motor program, adjustable infrared sensor switch program, and a program for running the prototype.

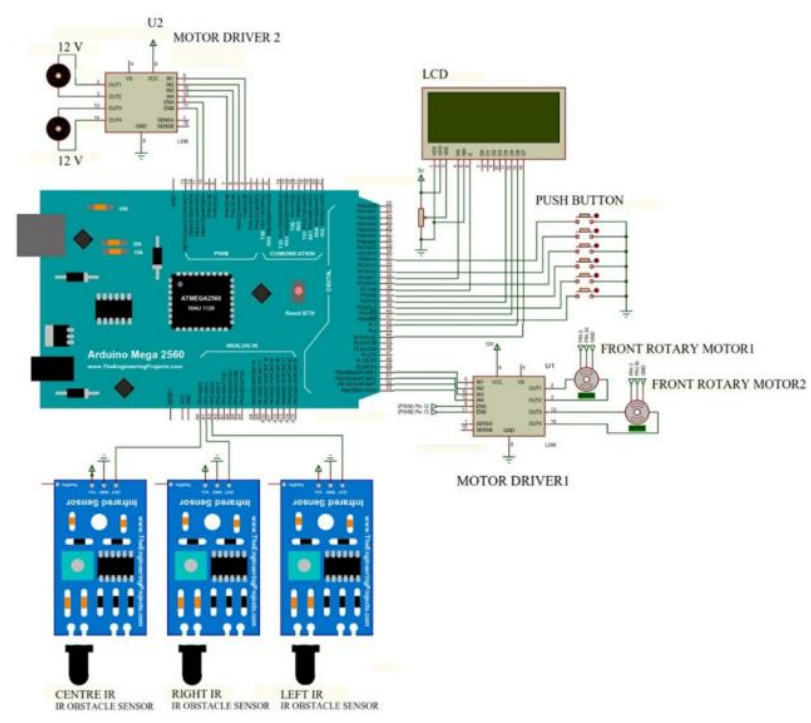

Figure. 2 Electrical circuits

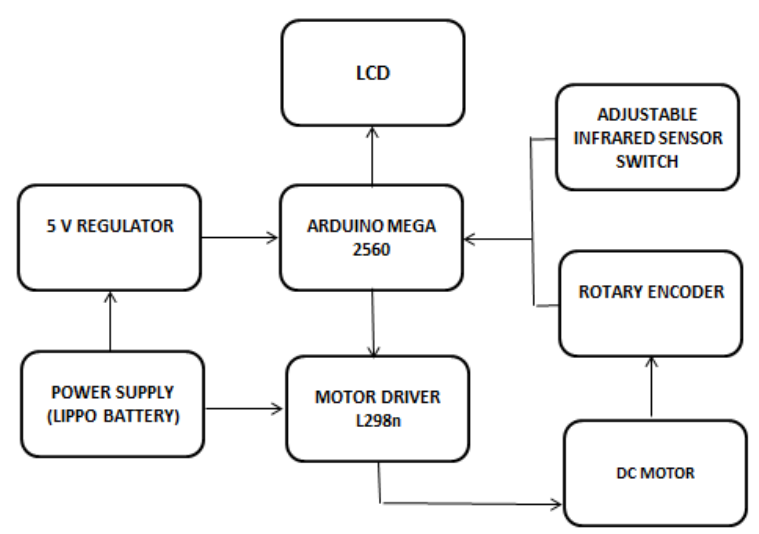

Figure. 3 Block diagrams of prototype
Each of the programs has its own specific use. The front DC motor with the fuzzy logic controller program is used to control the position of the sensor under the prototype; the rotary encoder program is used to process the input data from DC motor; and the side motor program is used to control the rotation speed of the motor on the side of the prototype.

Additionally, the function of the rotary encoder is to count the number of turns. Therefore, this program processes the number of pulses of each rotation and the diameter of the rope winder. Then, the diameter is processed into a circumference. The circumference will be calculated with pulse data and will produce a distance for each pulse.

The adjustable infrared sensor switch program is used to process the data from an adjustable infrared sensor switch. This sensor will be worth 0 or LOW if it detects an object at an adjusted distance and vice versa. If the sensor does not detect objects at a distance that has been adjusted, the data that come out will be worth 1 or HIGH. This sensor is used to detect underwater sediments.

\section{Front DC motor with the fuzzy logic controller}

Fuzzy is a smart system. Without knowing the appropriate modeling, the system can produce good control. Besides, this system is better than PID control because it can adapt to existing disturbances. This is precisely applied in this system, on ships where there are frequent changes in the flow of water suddenly. With PID control, it is actually able to solve this problem, but adjusting the PID parameter values still has to be done, while with fuzzy control it is not necessary.

The Fuzzy Logic Controller (FLC) was designed to control the front DC motor to raise and lower the sensor. The front DC motor, with parameters armature resistance $(\mathrm{Ra})=0.4 \mathrm{Ohm}$, and armature inductance $=0.05 \mathrm{H} \mathrm{[1]}$, adjusts the sensor position using the results of the rotary encoder.

Fig. 4 shows the closed loop control system with the FLC algorithm. The FLC input is error (E) and change of error (CE), while the output is change of control (CU). CU values are positive when $\mathrm{E}$ is positive and $\mathrm{CE}$ is negative (when reducing rise time),

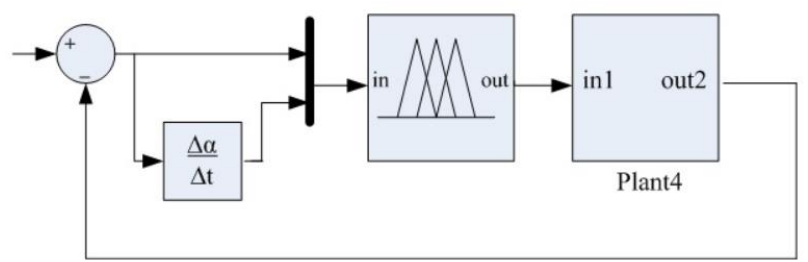

Figure. 4 Block diagram FLC 
Table 2. Rule of the fuzzy inference

\begin{tabular}{|l|l|}
\hline No & \multicolumn{1}{|c|}{ Rule } \\
\hline 1 & IF E is N AND CE is N THEN Sensor lowered \\
\hline 2 & IF E is N AND CE is Z THEN Sensor lowered \\
\hline 3 & IF E is N AND CE is P THEN Sensor lowered \\
\hline 4 & IF E is Z AND CE is N THEN Sensor lowered \\
\hline 5 & $\begin{array}{l}\text { IF E is Z AND CE is Z THEN Sensor doesn't } \\
\text { move }\end{array}$ \\
\hline 6 & IF E is Z AND CE is P THEN Sensor raised \\
\hline 7 & IF E is P AND CE is N THEN Sensor raised \\
\hline 8 & IF E is P AND CE is Z THEN Sensor raised \\
\hline 9 & IF E is P AND CE is P THEN Sensor raised \\
\hline
\end{tabular}

and the $\mathrm{CU}$ value is negative when $\mathrm{E}$ is negative and $\mathrm{CE}$ is negative (when reducing overshoot).

It used the triangular membership functions because it is the simplest form, the computation process is faster and has a good result. In section 4 it would be proven that using fuzzy logic controller and triangular membership function would get better results than using PID. Table 2, Rule of the fuzzy inference, shows nine rules of fuzzy inference used in this research. The output of the rule lowers the sensor, raises the sensor or the sensor doesn't move.

The result showed several conditions of the membership function where the fuzzy controller value has reached the convergent condition that is closest to the set point that has been determined. The best three conditions of the membership function of error (E) conditions are shown from Fig. 5 until Fig. 10.

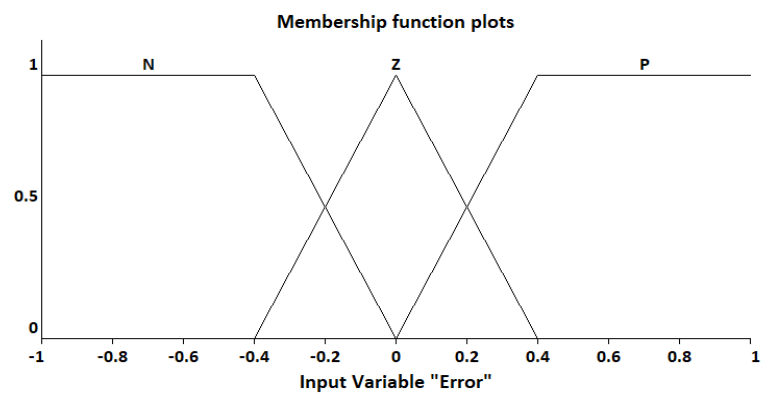

Figure. 5 The first FLC

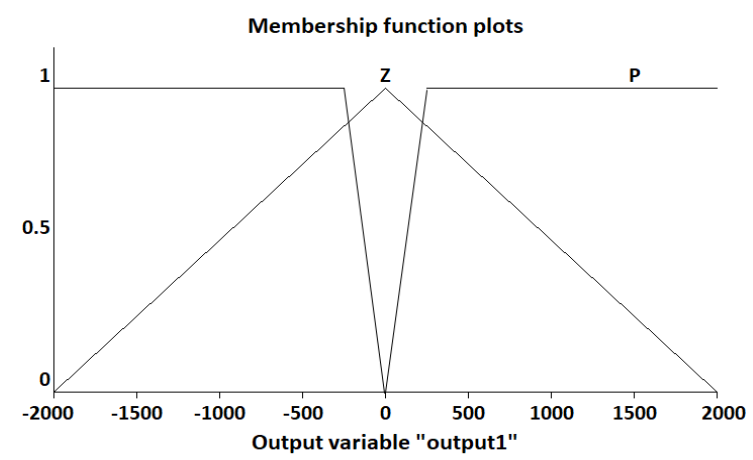

Figure. 6 Output of the first FLC
Changes are made to the input Error (E). Research was conducted for input E, the smaller the error $\mathrm{E}$ is taken, the better the results will be. The first change to input $\mathrm{E}$ was done by changing the membership function so that it corresponds to Fig. 5. Changes were only made to E but not to CE. Fig. 6 shows the resulting output.

Next, E was modified according to Fig. 7 with a fixed CE. the output obtained is shown in Fig. 8.

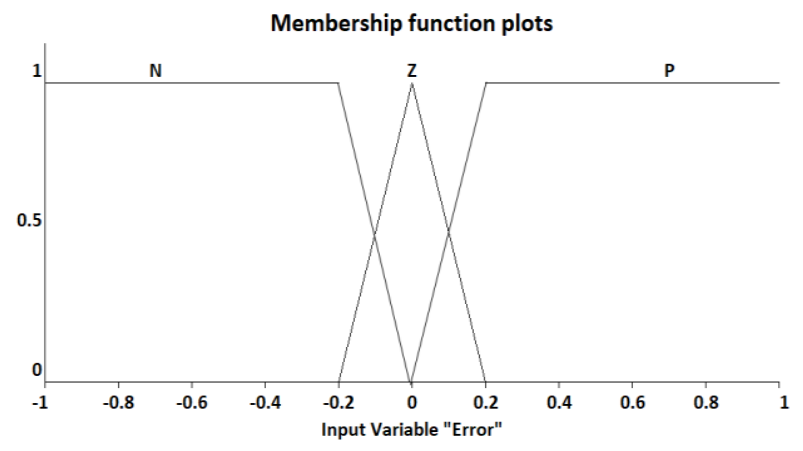

Figure. 7 The second FLC

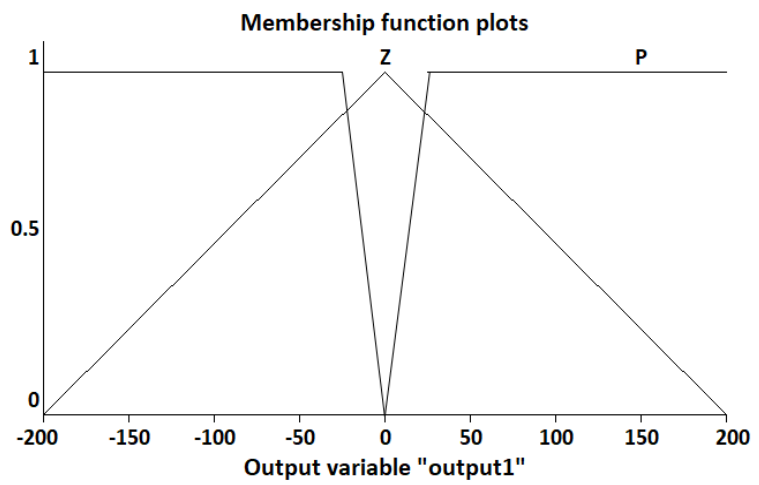

Figure. 8 The error of the second FLC

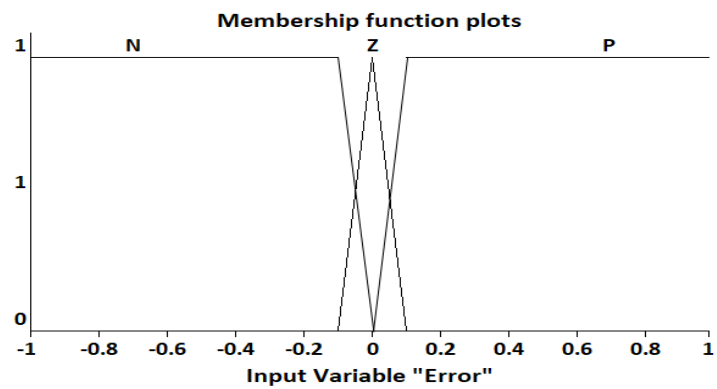

Figure. 9 The third FLC

Finally, the error E was attempted in a different composition as shown in Fig. 9.

The output obtained is seen in Fig. 10.

Fig. 11 shows the comparison of the three membership function, first, second and third FLC. The first FLC is as a black colour, the second FLC as a red colour, and the third as a blue FLC. 


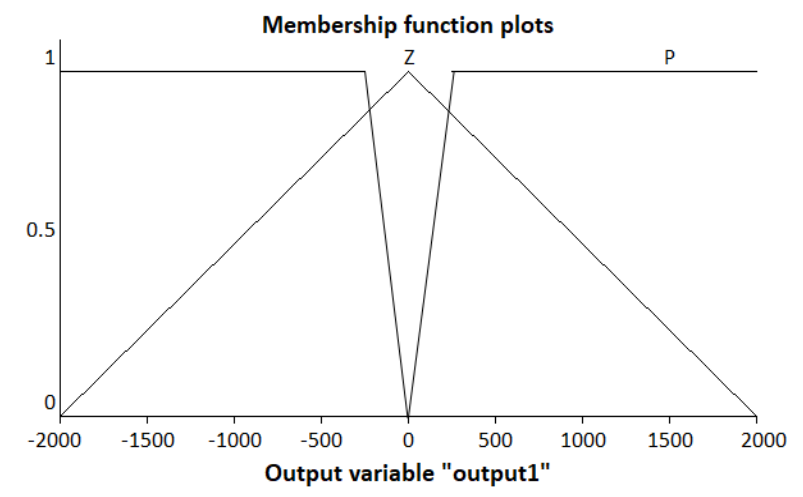

Figure. 10 Output of the third FLC

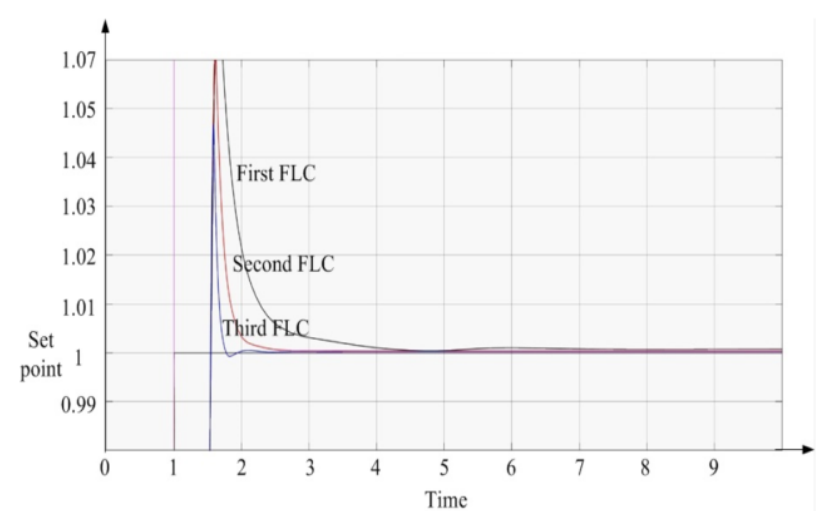

Figure. 11 Comparison of the three membership function

The third membership function (Fig. 9 and Fig. 10) is the best performance of the FLC, because it could converge to the set point (black color) in Fig. 11 with a minimal oscillation. However, the three membership functions were still much better than if we had used the PID algorithm. The proof of this statement will be explained in the following section.

\section{FLC compare with PID}

The PID algorithm was applied using the same plant used by the FLC algorithm. The search for the best $\mathrm{P}$ value is described in Fig. 12.

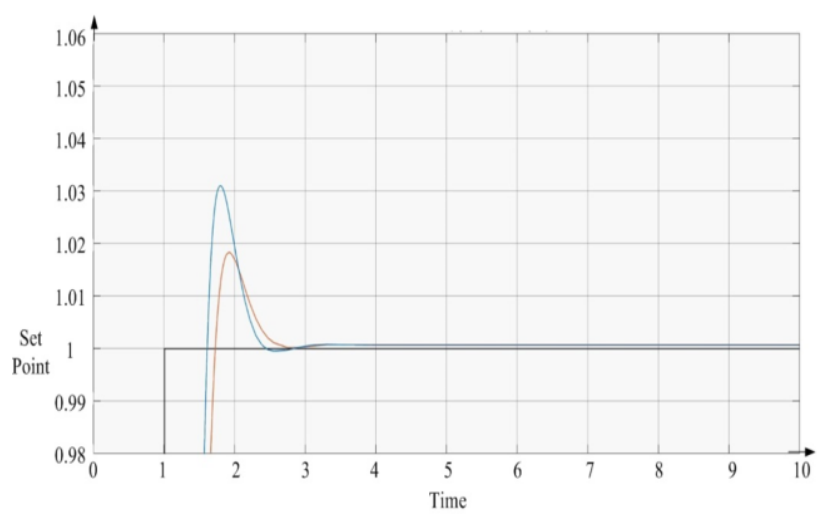

Figure. 12 Comparison of the two PID, $\mathrm{P}=112,5$ (blue) and $\mathrm{P}=100$ (red)

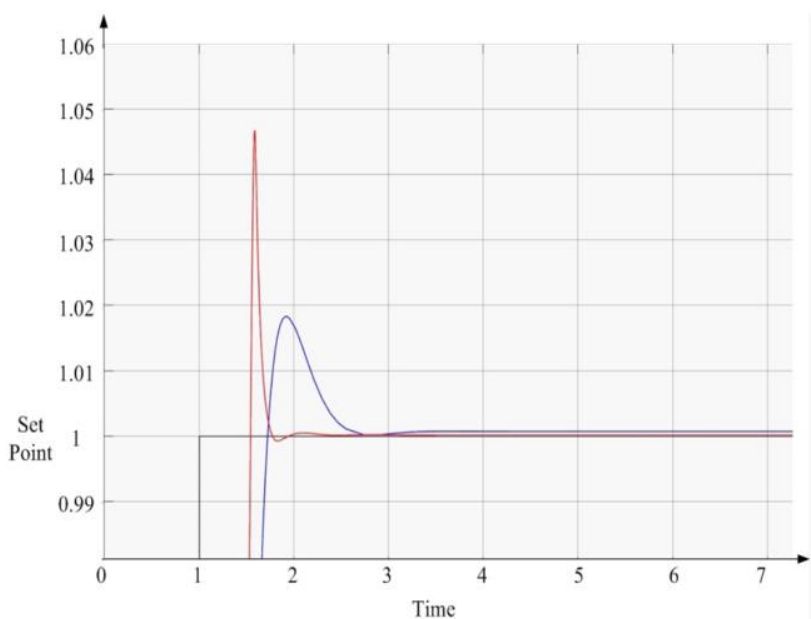

Figure. 13 Comparison of best FLC (red) and best PID (blue)

The PID algorithm reached its optimum value at $P=100$, and reached a convergent condition in more than 4 seconds with an error rate of 0.001 .

However, although the best output for the PID algorithm is obtained at $P=100$, the front DC motor control process using FLC is still better, because it oscillates less and reaches the set point faster, FLC algorithm reaches a convergent condition in less than 4 seconds with an error rate 0.0005 . This is shown in Fig. 13. The front DC motor control process with three best FLCs and two best PID can be seen in Fig. 14.

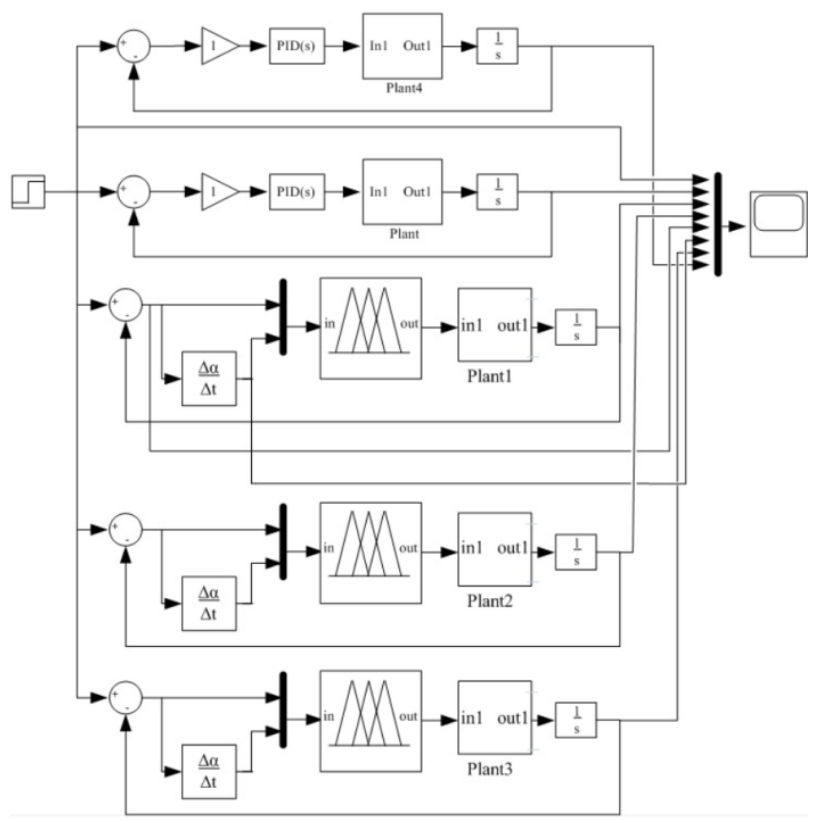

Figure. 14 DC motor control process with three FLCs and PID 


\section{How to measure the length, height and width of the sediment}

The side DC motor with the program for running prototype is used to move the device forward or rotating, to calculate the length, width and height of the sediment. The side DC motor works after the front DC motor.

Fig. 15 explains program for running prototype to measure length and height of the sediment, whereas Fig. 16 shows how to measure the width of the sediment. It will be transcribed into matrices.

There were 2 (two) types of transformation matrices, i.e. translation and rotation, with translational displacement of the $\mathrm{x}$-axis, $\mathrm{y}$-axis, and $\mathrm{z}$-axis in a coordinate system.

$$
\left[\begin{array}{c}
x^{\prime} \\
y^{\prime} \\
z^{\prime} \\
1
\end{array}\right]=\left[\begin{array}{lllr}
1 & 0 & 0 & t_{x} \\
0 & 1 & 0 & t_{y} \\
0 & 0 & 0 & t_{z} \\
0 & 0 & 0 & 1
\end{array}\right]\left[\begin{array}{l}
x \\
y \\
z \\
1
\end{array}\right]
$$
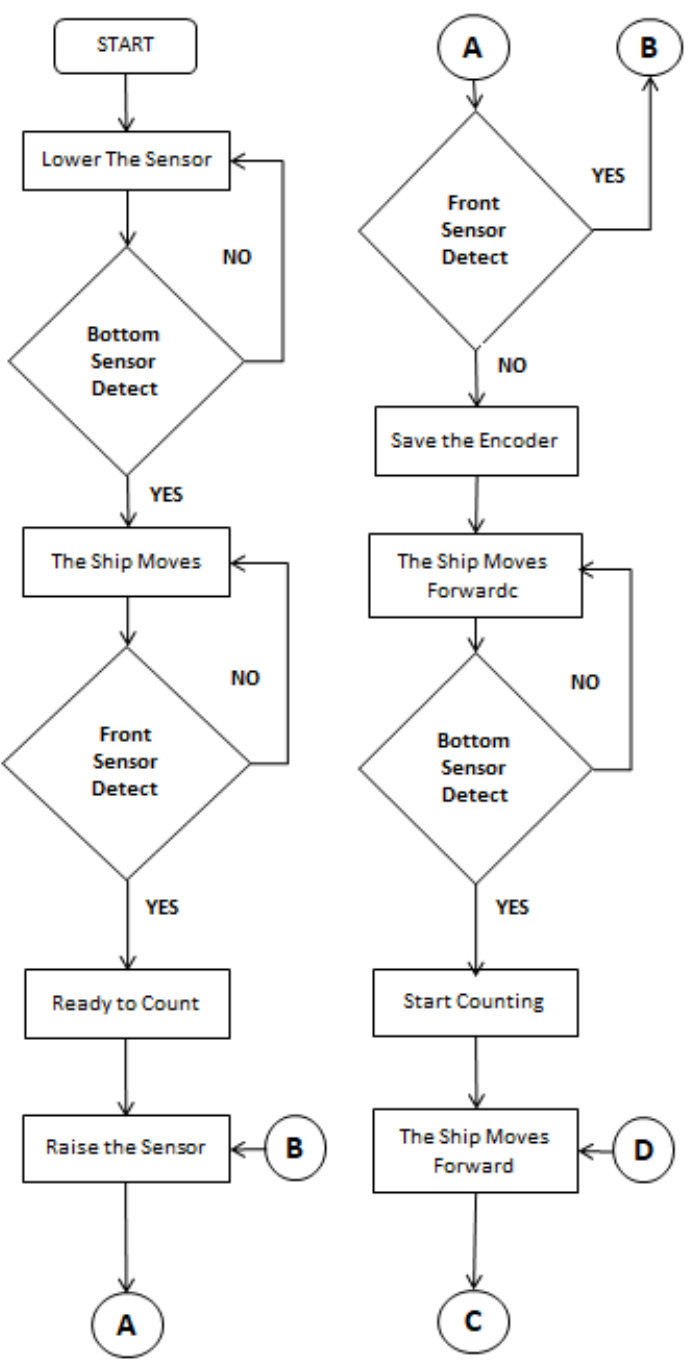

Figure. 15 Flowchart of prototype (1)
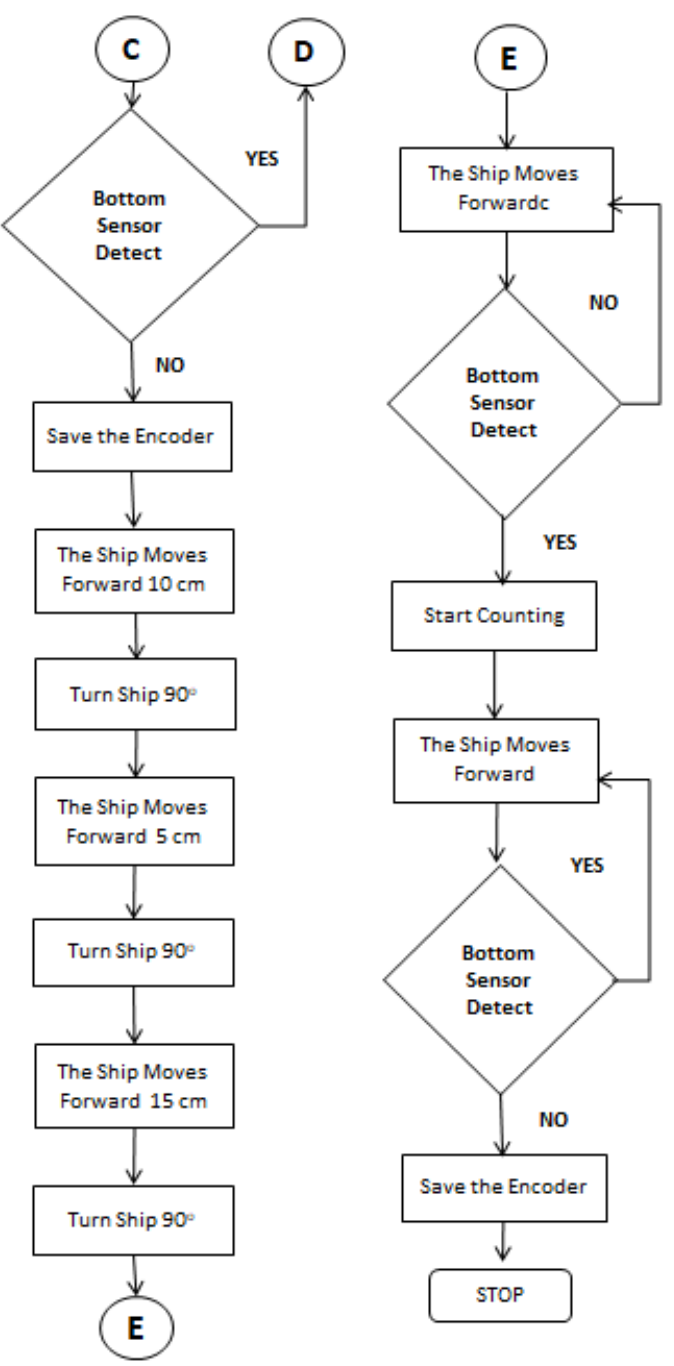

Figure. 16 Flowchart of prototype (2)

Matrix rotations with respect to the $\mathrm{x}$-axis, $\mathrm{y}$-axis, and z-axis, are shown in matrix: [17].

Rotation matrix with respect to the $\mathrm{X}$-axis:

$$
\left[\begin{array}{l}
x^{\prime} \\
y^{\prime} \\
z^{\prime} \\
1
\end{array}\right]=\left[\begin{array}{cccc}
1 & 0 & 0 & t_{x} \\
0 & \cos \alpha & -\sin \alpha & t_{y} \\
0 & \sin \alpha & \cos \alpha & t_{z} \\
0 & 0 & 0 & 1
\end{array}\right]\left[\begin{array}{l}
x \\
y \\
z \\
1
\end{array}\right]
$$

Rotation matrix with respect to the $\mathrm{Y}$-axis:

$$
\left[\begin{array}{c}
x^{\prime} \\
y^{\prime} \\
z^{\prime} \\
1
\end{array}\right]=\left[\begin{array}{cccc}
\cos \alpha & 0 & \sin \alpha & t_{x} \\
0 & 1 & 0 & t_{y} \\
-\sin \alpha & 0 & \cos \alpha & t_{z} \\
0 & 0 & 0 & 1
\end{array}\right]\left[\begin{array}{l}
x \\
y \\
z \\
1
\end{array}\right]
$$

Rotation matrix with respect to the Z-axis:

$$
\left[\begin{array}{c}
x^{\prime} \\
y^{\prime} \\
z^{\prime} \\
1
\end{array}\right]=\left[\begin{array}{cccc}
\cos \alpha & -\sin \alpha & 0 & t_{x} \\
\sin \alpha & \cos \alpha & 0 & t_{y} \\
0 & 0 & 1 & t_{z} \\
0 & 0 & 0 & 1
\end{array}\right]\left[\begin{array}{l}
x \\
y \\
z \\
1
\end{array}\right]
$$




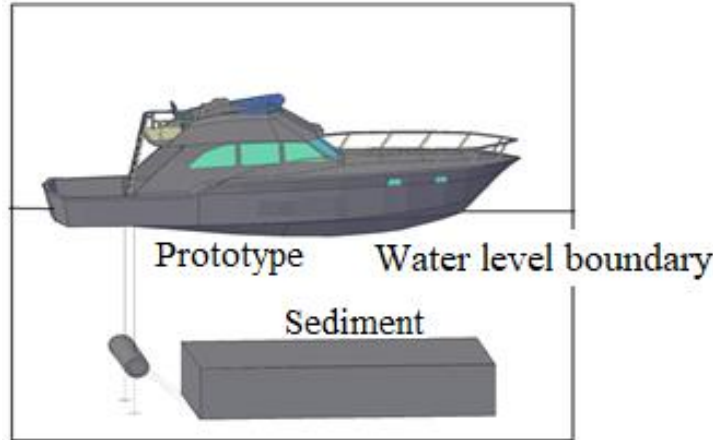

Figure. 17 The position after the front sensor detects the sediment, then the prototype would go up

The movement of the prototype follows the rules of translation and rotation, assuming that the position of the sensor on the water surface is the center $(0,0,0)$. The front DC motor lowers the sensor, and will try to detect an object. In this condition, if the bottom sensor detects an object, then the data from the rotary encoder will be counted. It should be noted that the front DC motor serves to raise and lower the sensor, while the side DC motor serves to move the device forward or rotate

The flowchart in Fig. 15 and Fig. 16 explains that after the bottom sensor detects an object, the prototype will move forward until the front sensor detects the object in front of it. When moving forward, the translation matrix will represent the movement of the prototype. Suppose the prototype moves forward by $\mathrm{m} 1 \mathrm{~cm}$, then the transition matrix becomes:

$$
\left[\begin{array}{cccc}
1 & 0 & 0 & 0 \\
0 & 1 & 0 & m 1 \\
0 & 0 & 1 & 0 \\
0 & 0 & 0 & 1
\end{array}\right]\left[\begin{array}{l}
0 \\
0 \\
0 \\
1
\end{array}\right]=\left[\begin{array}{c}
0 \\
m 1 \\
0 \\
1
\end{array}\right]
$$

Furthermore, the prototype would go up and the front sensor detects the object in front of it until it did not detect it. Fig. 17 and Fig. 18 show this condition. The rotary encoder would record the upward movement as the height of sediment $\mathrm{h}$ :

$$
\left[\begin{array}{llll}
1 & 0 & 0 & 0 \\
0 & 1 & 0 & 0 \\
0 & 0 & 1 & h \\
0 & 0 & 0 & 1
\end{array}\right]\left[\begin{array}{c}
0 \\
m 1 \\
0 \\
1
\end{array}\right]=\left[\begin{array}{c}
0 \\
m 1 \\
\boldsymbol{h} \\
1
\end{array}\right]
$$

The prototype began to move forward $(\mathrm{m} 2 \mathrm{~cm})$ and moved as far as sediment length 1 , or the position become $\mathrm{m} 2+1$.

$$
\left[\begin{array}{ccccc}
1 & 0 & & 0 & 0 \\
0 & 1 & & 0 & m \boldsymbol{2}+\boldsymbol{l} \\
0 & 0 & & 1 & 0
\end{array}\right]\left[\begin{array}{c}
0 \\
m 1 \\
\boldsymbol{h} \\
1
\end{array}\right]=\left[\begin{array}{c}
0 \\
m 1+m 2+\boldsymbol{l} \\
\boldsymbol{h} \\
1
\end{array}\right]
$$

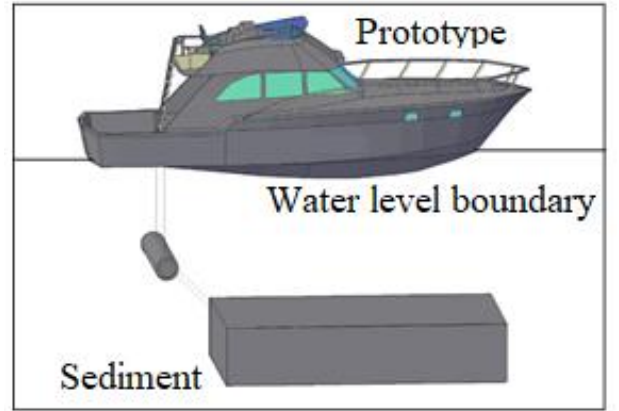

Figure. 18 The prototype went up and the front sensor detected the topmost sediment

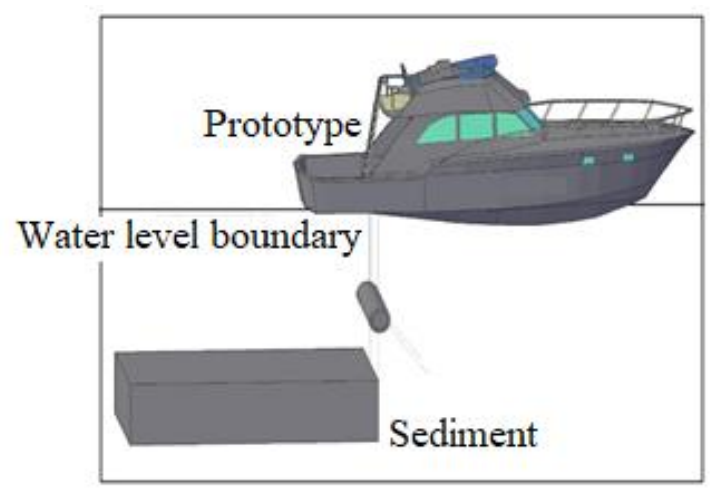

Figure. 19 Prototype moved as fast as sediment length

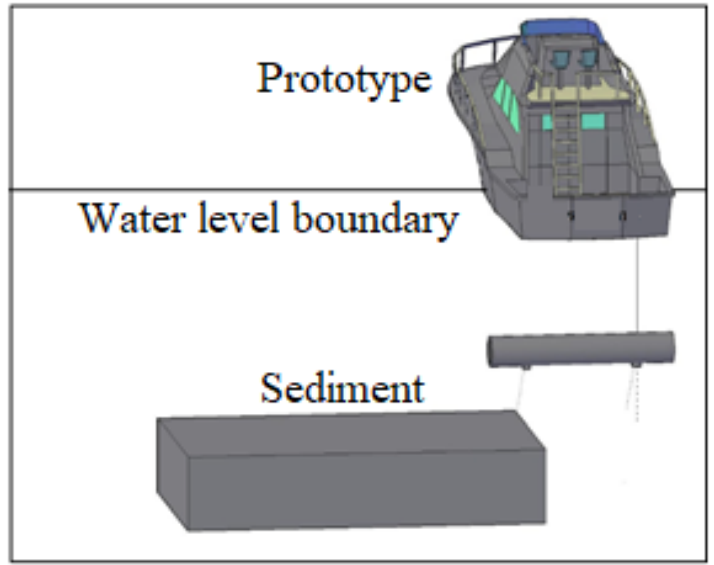

Figure. 20 The prototype rotated $90^{\circ}$ along Yaxis, the center position of the ship did not change

Fig. 19 shows the movement of the prototype as far as the sediment length.

After obtaining the sediment length, the prototype would search for the sediment width according to Fig. 20 . The prototype would go forward along $10 \mathrm{~cm}$, then rotate $90^{\circ}$ counterclockwise with the Y-axis to the center: $(0, m 1+m 2+1, h)$.

Here is the rotation matrix where the prototype is rotated $90^{\circ}$. 


$$
\begin{gathered}
{\left[\begin{array}{cccc}
\cos 90 & 0 & \sin 90 & 0 \\
0 & 1 & 0 & 0 \\
-\sin 90 & 0 & \cos 90 & 0 \\
0 & 0 & 0 & 1
\end{array}\right]\left[\begin{array}{c}
0 \\
10 \\
0 \\
0
\end{array}\right]+\left[\begin{array}{c}
0 \\
m 1+m 2+\boldsymbol{l} \\
\boldsymbol{h} \\
1
\end{array}\right]} \\
=\left[\begin{array}{c}
m 1+m 2+\boldsymbol{l}+10 \\
\boldsymbol{h} \\
1
\end{array}\right]
\end{gathered}
$$

The image for the next process is analogous to the three images above; the difference only depends on the movement of the prototype according to its axis. Next, it moved forward $5 \mathrm{~cm}$ along the $\mathrm{X}$-axis.

$$
\begin{array}{r}
{\left[\begin{array}{cccc}
1 & 0 & 0 & 5 \\
0 & 1 & 0 & 0 \\
0 & 0 & 1 & 0 \\
0 & 0 & 0 & 1
\end{array}\right]\left[\begin{array}{c}
0 \\
m 1+m 2+\boldsymbol{l}+10 \\
\boldsymbol{h} \\
1 \\
5
\end{array}\right]} \\
=\left[\begin{array}{c}
m 1+m 2+\boldsymbol{l}+10 \\
\boldsymbol{h} \\
1
\end{array}\right]
\end{array}
$$

Then, it rotated $90^{\circ}$ counterclockwise to the $\mathrm{X}$-axis, with the center: $(0, m 1+m 2+1+10, h)$.

$$
\begin{gathered}
{\left[\begin{array}{cccc}
1 & 0 & 0 & 0 \\
0 & \cos 90 & -\sin 90 & 0 \\
0 & \sin 90 & \cos 90 & 0 \\
0 & 0 & 0 & 1
\end{array}\right]\left[\begin{array}{c}
5-0 \\
0 \\
\boldsymbol{h}-\boldsymbol{h} \\
1-1
\end{array}\right]+} \\
0 \\
{\left[\begin{array}{c}
51+m 2+\boldsymbol{l}+10 \\
\boldsymbol{h} \\
1
\end{array}\right]=\left[\begin{array}{c}
m 1+m 2+\boldsymbol{l}+10 \\
\boldsymbol{h} \\
1
\end{array}\right](10)}
\end{gathered}
$$

It moved forward $15 \mathrm{~cm}$ along the $\mathrm{Y}$-axis,

$$
\begin{gathered}
{\left[\begin{array}{cccc}
1 & 0 & 0 & 0 \\
0 & 1 & 0 & 15 \\
0 & 0 & 1 & 0 \\
0 & 0 & 0 & 1
\end{array}\right]\left[\begin{array}{c}
5 \\
m 1+m 2+\boldsymbol{l}+10 \\
\boldsymbol{h} \\
1 \\
5
\end{array}\right]=} \\
{\left[\begin{array}{c}
m 1+m 2+\boldsymbol{l}+25 \\
\boldsymbol{h} \\
1
\end{array}\right]}
\end{gathered}
$$

then turned $90^{\circ}$ counterclockwise with the center: $(5$, $\mathrm{m} 1+\mathrm{m} 2+\mathrm{l}+10, \mathrm{~h})$ to the Y-axis.

$$
\begin{aligned}
& {\left[\begin{array}{cccc}
\cos 90 & 0 & \sin 90 & 0 \\
0 & 1 & 0 & 0 \\
-\sin 90 & 0 & \cos 90 & 0 \\
0 & 0 & 0 & 1
\end{array}\right]\left[\begin{array}{c}
5-5 \\
15 \\
\boldsymbol{h}-\boldsymbol{h} \\
1-1
\end{array}\right]} \\
& \left.\begin{array}{c}
m 2+\boldsymbol{l}+10 \\
\boldsymbol{h} \\
1
\end{array}\right]=\left[\begin{array}{c}
m 1+m 2+\boldsymbol{l}+25 \\
\boldsymbol{h} \\
1
\end{array}\right]
\end{aligned}
$$

Table 3. Error measurement

\begin{tabular}{|l|l|}
\hline $\begin{array}{l}\text { Type of } \\
\text { Measurement }\end{array}$ & $\begin{array}{l}\text { Error Measurement } \\
\text { (Percentage) }\end{array}$ \\
\hline Height & $21 \%$ \\
\hline Length & $31 \%$ \\
\hline Width & $47 \%$ \\
\hline
\end{tabular}

The steps were then repeated from the beginning to find the length and width of the sediment, $\mathrm{w} \mathrm{cm}$.

\section{The fuzzy intuitive sets for making decision to improve measurement results}

In the previous section, there were errors in the calculation of length, width and height. Error percentage is shown in Table 3.

Evidently, the "Height" value, had the smallest error. For "Lenght" and "Width" measurement still had error measurement more than $30 \%$. So, it will be examined whether it is necessary to improve these measurements by predicting the correct size or not. The Fuzzy Intuitive Sets will be used to make the decision.

first, it will be expressed in a mathematical statement as follows:

$\alpha$ :"Height" measurements were declared not valid (need to be fixed)

$\beta_{1}$ :"Length" measurements were declared not valid (need to be fixed)

$\beta_{2}$ :"Width" measurements were declared not valid (need to be fixed)

$\beta_{3}$ :"Height", "Length", and "Width" were declared not valid (need to be fixed)

Because for error values greater than $25 \%$ was not accurate, it can be agreed that the "Height" value need not be fixed. The estimate of uncertainty is realized due to $\alpha$. Because $\alpha$ should be mainly excluded from the possibility of data correction, therefore $\beta=\beta_{1} \vee \beta_{2} \vee \beta_{3}$.

Fuzzy Sets: $\underline{A}=\{\alpha|\mu(\alpha) ; \beta|\}$,

$$
\mu(\alpha)+\mu(\beta) \leq 1
$$

The Intuitive Fuzzy Sets (IFS) F:

$\mathrm{F}=\mu(\alpha)\{\alpha /(\mu(\alpha) ; \nu(\alpha)) ; \beta /(\mu(\beta) ; \nu(\beta))\}$.

From Table 3, it was assumed that:

$\mu(\alpha)=0.2 ; v(\alpha)=0.7$

$\pi(\alpha)=1-\mu(\alpha)-v(\alpha)=0.1$.

The Intuitive Fuzzy Sets (IFS) $\mathrm{F}$ became:

$\mathrm{F}=\mu(\alpha)\{\alpha /(0.2 ; 0.7) ; \beta /(0.8 ; 0.1)\}$. 
By using Eq. (1), uncertainty $H(A)(\alpha)$ :

$$
\begin{aligned}
\mathrm{H}(\mathrm{A})(\alpha) & =-\mu(\alpha) \cdot \log _{2} \mu(\alpha)- \\
& (1-\mu(\alpha)) \cdot \log _{2}(1-\mu(\alpha))
\end{aligned}
$$

Then,

$$
\begin{aligned}
\mathrm{H}\left(A_{1}(\alpha)\right) & =-\mu(\alpha) \cdot \log _{2} \mu(\alpha)- \\
& (1-\mu(\alpha)) \cdot \log _{2}(1-\mu(\alpha)) \\
& =-(0.2) \log _{2} 0.2-(0.8) \cdot \log _{2}(0.8) \\
& =0.464+0.256 \\
& =0.72 \\
\mathrm{H}\left(A_{2}(\alpha)\right) & =-v(\alpha) \cdot \log _{2} v(\alpha)- \\
& (1-v(\alpha)) \cdot \log _{2}(1-v(\alpha)) \\
& =-(0.7) \log _{2} 0.7-(0.3) \cdot \log _{2}(0.3) \\
& =0.3605+0.5211 \\
& =08816 \\
\mathrm{H}\left(A_{3}(\alpha)\right) & =-\pi(\alpha) \cdot \log _{2} \pi(\alpha)- \\
& (1-\pi(\alpha)) \cdot \log _{2}(1-\pi(\alpha)) \\
& =-(0.1) \log _{2} 0.1-(0.9) \cdot \log _{2}(0.9) \\
& =0.032+0.1350 \\
& =0.167
\end{aligned}
$$

By Eq. (2)

$$
\begin{array}{r}
\mathrm{H}(\mathrm{F})(\alpha) \\
\mathrm{H}\left(A_{3}(\alpha)\right)
\end{array}=\mathrm{H}\left(A_{1}(\alpha)\right)+\mathrm{H}\left(A_{2}(\alpha)\right)+
$$

And also Eq. (2), the result became

$$
H(F)(\alpha)=0.72+0.8816+0 \text {. }
$$

With the Eq. (3) normalized form of information:

$$
I_{\alpha}(F)_{n o r m}=1-\left[\frac{\mathrm{H}(F)(\alpha)}{3}\right]
$$

and plug in a value of $H(F)(\alpha)$, so that

$$
I_{\alpha}(F)_{\text {norm }}=1-\left[\frac{1,7686}{3}\right]=0.41 \text {. }
$$

Semantic Information became

$$
I(F)^{S}(\alpha)=\left\{\begin{array}{l}
-I(F)_{\text {norm }} ; 0 \leq \mu(\alpha) \leq 0.5 \\
I(F)_{\text {norm }} ; 0.5 \leq \mu(\alpha) \leq 1
\end{array}\right.
$$

and $-1 \leq I(F)^{S}(\alpha) \leq 1$ and because $\mu(\alpha)=0.2$, then $I(F)^{S}(\alpha)=m-0.41$

By using Eq. (5) the uncertainty $H(\alpha)$ :

$$
\begin{array}{r}
\mathrm{H}(\alpha)=-\left(\mu(\alpha) \cdot \log _{2} \mu(\alpha)+v(\alpha) \cdot \log _{2} v(\alpha)+\right. \\
\left.\pi(\alpha) \cdot \log _{2} \pi(\alpha)\right)
\end{array}
$$

Then,

$$
\begin{aligned}
\mathrm{H}(\alpha)= & -\left((0.2) \log _{2} 0.2+(0.7) \log _{2} 0.7+\right. \\
& \left.(0.1) \log _{2} 0.1\right) \\
= & -(-0464-0.3605-0.032) \\
= & 0.8565
\end{aligned}
$$

And from Eqs. (3) and (4)

$$
\begin{aligned}
I_{\alpha}(\mathrm{F})_{\text {norm }} & =1-\frac{H(\alpha)}{\log _{2} 3} \\
& =1-\frac{0.8565}{1.585} \\
& =1-0.54 \\
& =0.46 \\
I(F)^{S}(\alpha) & =-0.46
\end{aligned}
$$

The uncertainty of $\alpha$ against $\beta$ could be calculated by Eq. (6):

$$
\begin{aligned}
H(\mathrm{~F}, \alpha) & =-\left(\mu(\alpha) \log _{2} \mu(\alpha)+\left(\mu(\beta) \log _{2} \mu(\beta)\right)\right. \\
& =-\left[0.2 \log _{2} 0.2+\left(0.8 \log _{2} 0.8\right)\right] \\
& =0.464+0.256 \\
& =0.72
\end{aligned}
$$

Relevant semantized information with respect to $\alpha$ :

$$
I^{S}(\mathrm{~F}, \alpha)=1-H(\mathrm{~F}, \alpha)
$$

So that $I^{S}(F, \alpha)=1-0.72=0.28$

Because $0 \leq \mu(\alpha) \leq 0,5$

Then $I^{S}(F, \alpha)=-0.28$

When proceeded semanticization with

$$
H(\mathrm{~F}, \alpha)=2 \min (\mu(\alpha) ;(1-\mu(\alpha)))
$$

Then,

$H(\mathrm{~F}, \alpha)=2(0.2)=0.4$

$I^{S}(\mathrm{~F}, \alpha)=1-H(\mathrm{~F}, \alpha)=1-0.4=0.6$

Because $0 \leq \mu(\alpha) \leq 0.5$

so that $I^{S}(\mathrm{~F}, \alpha)=-0.6$.

[18], [19].

If these results are tabulated, the results are shown in Table 4 below.

It could be seen that the uncertainty of $\alpha$ is quite large, which is more than 0.70 , and the information of $\alpha$ is very small, because in the range of -0.6 to

Table 4. Uncertainty and information

\begin{tabular}{|c|l|c|}
\hline Classification & Uncertainty & Information \\
\hline$\alpha$ & 0.8565 & -0.46 \\
\hline$\alpha$ & 1.7686 & -0.41 \\
\hline$\alpha$ against $\beta$ & 0.72 & -0.28 \\
\hline$\alpha$ against $\beta$ & 0.72 & -0.6 \\
\hline
\end{tabular}


-0.2 , so that the measurement of "height" does not need to be corrected (or $\alpha$ must be excluded). However, because the $\beta_{3}$ statement is the average of the overall measurement, it must be decided to improve the measurement with predictive LMS.

\section{Least mean square adaptive predictive for minimizing error measurement}

From the results obtained in section 6, only "height" is the valid measurement, the others cannot be considered valid. So, it is necessary to carry out a predictive LMS Adaptive process to fix the errors occurred. The inputs are data, which consists of measurement results for height, length, and width that still contain measurement errors.

The block diagram of the adaptive predictive least mean square (LMS) was shown by the block diagram in Fig. 21.

The values of $\mathrm{d}$ and $\mathrm{x}$ are targets and inputs, respectively. Both are the same data, but input $x$ is the target that is delayed by one sample [20-22].

Least Mean Square Adaptive algorithms were used to solve linear estimation problems like the one depicted in Fig. 22, where the input vector

$x_{k}=\left[\begin{array}{lll}x_{1 k} x_{2 k} & \cdots & x_{L k}\end{array}\right]^{T}$ and desired response $d_{k} \in R$ are jointly stationary random processes. The equations for weight, output and error are shown in Eqs. (21) (23) below.

The weight vector $w_{k}$ :

$$
w_{k}=\left[w_{1 k} w_{2 k} \cdots w_{L k}\right]^{T}
$$

Output $y_{k}$,

$$
y_{k}=x_{k}^{T} w_{k}
$$

and error $\varepsilon_{k}$ :

$$
\varepsilon_{k}=d_{k}-y_{k}
$$

The Mean Square Error (MSE) is defined as

$$
\xi k=E\left[\varepsilon_{k}^{2}\right]
$$

and it is a quadratic function of the weight vector. The optimal weight vector that minimizes $\xi k$ is given by

$$
w *=R^{-1} p
$$

where

$$
R=E\left[x_{k} x_{k}^{T}\right]
$$

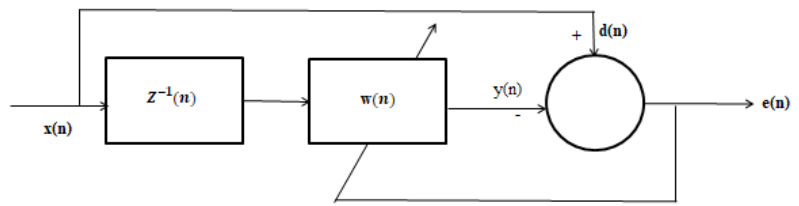

Figure. 21 Adaptive predictive LMS block diagram

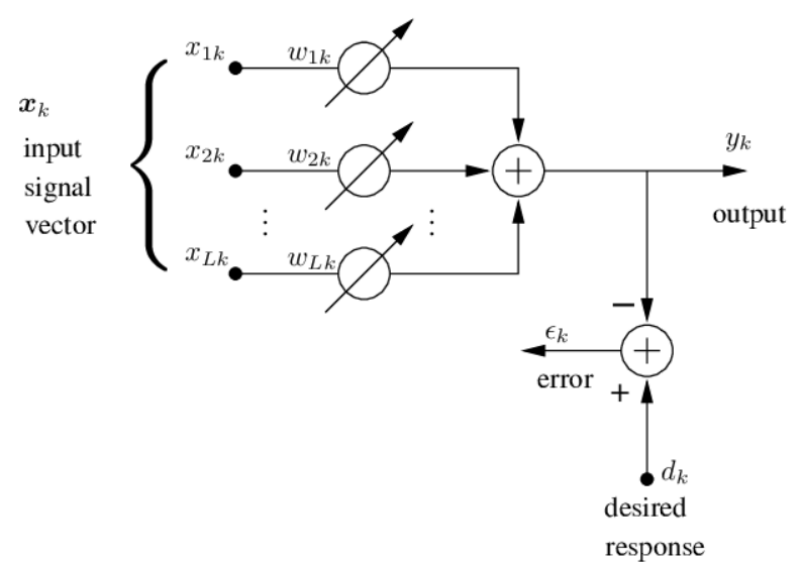

Figure. 22 Adaptive linear combiner

is the input autocorrelation matrix (assumed to be full rank), and

$$
p=E\left[x_{k} d_{k}\right]
$$

is the cross-correlation vector. The minimum MSE (MMSE) was obtained using $w *$ is denoted by $\xi *$.

Often in practice, $R^{-1} p$ cannot be calculated due to the lack of knowledge of the statistics $R$ and $p$. However, when samples of $x_{k}$ and $d_{k}$ are available, they can be used to iteratively adjust the weight vector to obtain an approximation of $w *$. The simplest and most widely used algorithm for this is LMS. It performs instantaneous gradient descent adaptation of the weight vector:

$$
w_{k+1}=w_{k}+2 \mu \varepsilon_{k} x_{k}
$$

The step size parameter is $\mu$ and the initial weight vector $\mathrm{w}_{0}$ is arbitrarily set by the user. The MSE sequence $\xi \mathrm{k}$ corresponding to the sequence of adapted weight vectors wk is commonly known as the learning curve [23-25].

The results of measurements conducted in Section 5, still contained measurement errors. The existence of measurement error is shown in Fig. 23. There were no precise $40 \mathrm{~cm}$ measurements made by the adjustable infrared sensor, which was recorded by a rotary encoder.

Adaptive LMS prediction can minimize the error up to a one-thousandth level of accuracy. The $\mu$ parameter greatly determines the speed and accuracy of adaptation. With various values of $\mu$ being tested, 
the accuracy of measurement is shown in Fig. 24.

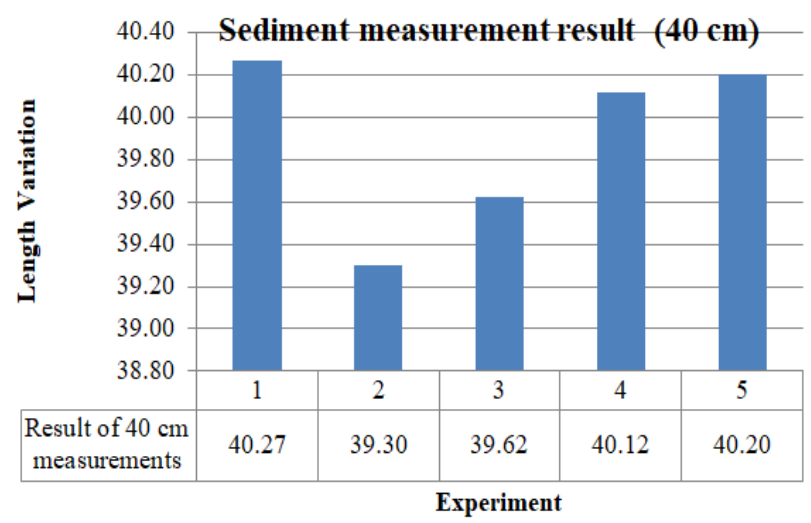

Figure. 23 Measurement of $40 \mathrm{~cm}$ sediment

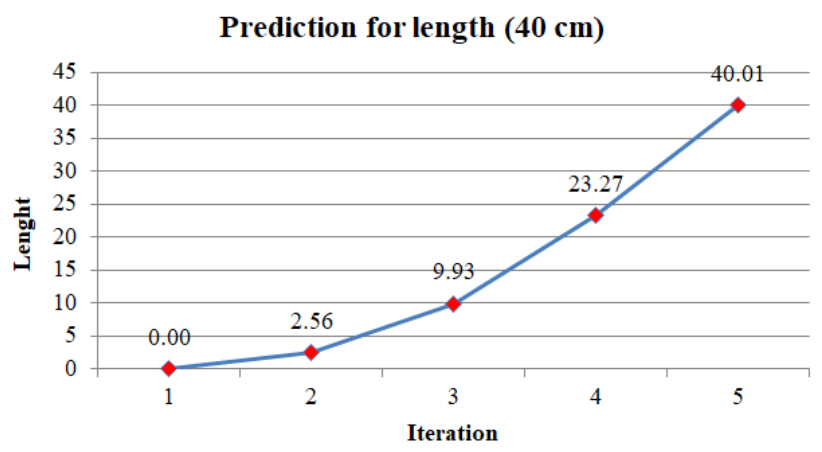

Figure. 24 Prediction for length $(40 \mathrm{~cm})$

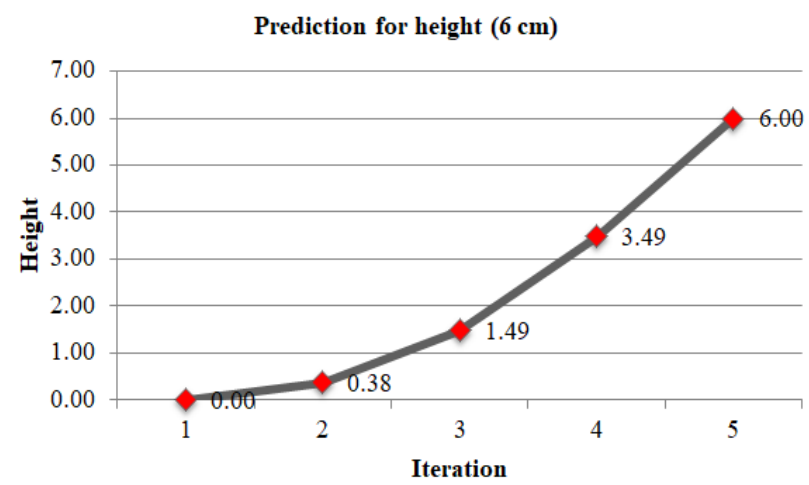

Figure. 25 Prediction for height $(6 \mathrm{~cm})$

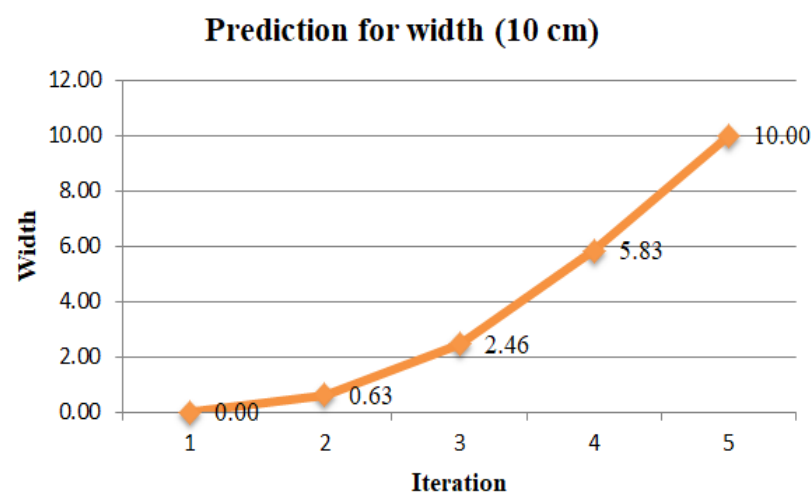

Figure. 26 Prediction for width $(10 \mathrm{~cm})$
Fig. 24 shows that $40 \mathrm{~cm}$ length measurement could be achieved in five iterations. The prediction process for the measurement results of width and height was done analogously. Fig. 25 until Fig. 29 shows the prediction process for another measurements.

All desired measurements can be achieved in 5 iterations. Table 5. Predictive for height $(12 \mathrm{~cm})$ shows that the size of the object was inversely proportional to the parameter value $\mu$.

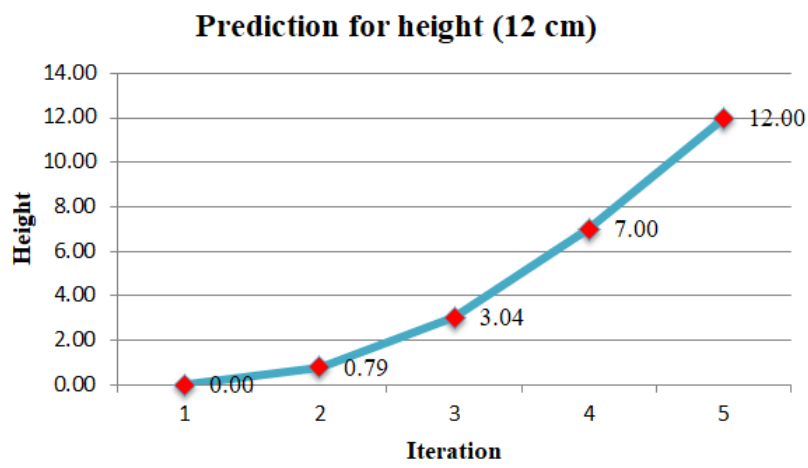

Figure. 27 Prediction for height $(12 \mathrm{~cm})$

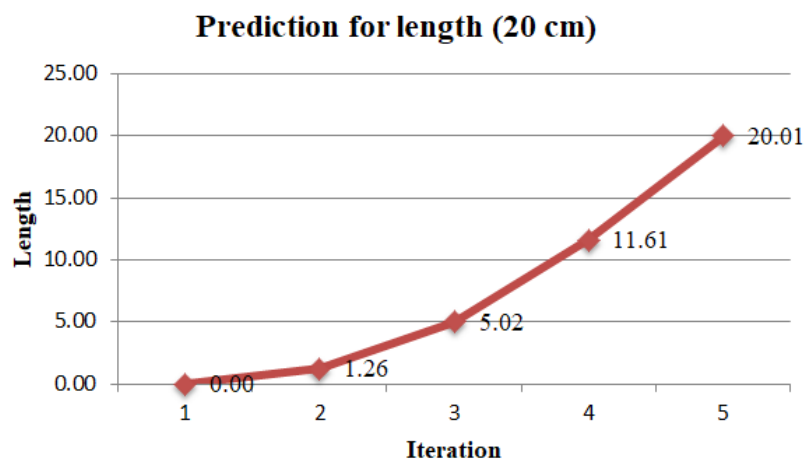

Figure. 28 Prediction for length $(20 \mathrm{~cm})$

Prediction for width $(20 \mathrm{~cm})$

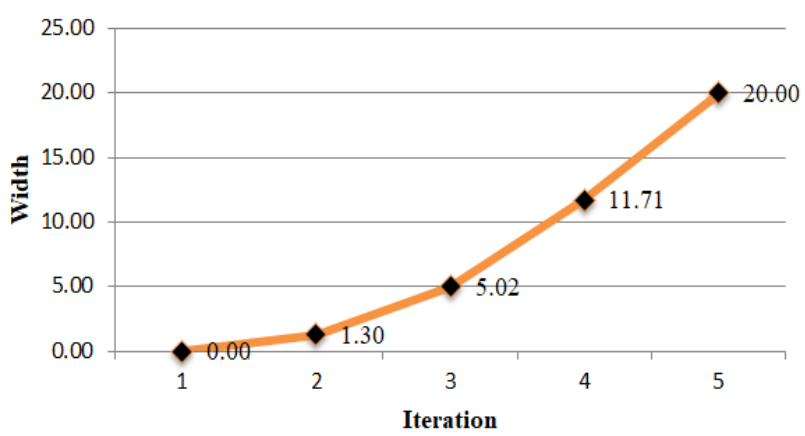

Figure. 29 Prediction for width $(20 \mathrm{~cm})$

This is due to the more careful adaptive systems in maintaining the occurrence of high oscillations. Step size $\mu$ had values ranging from 0.00002 until 0.0003 , depending on the size of the object. Table 3 . 
Table 5. Optimum step size and error

\begin{tabular}{|l|l|l|l|}
\hline Size & Measurement & $\begin{array}{l}\text { Optimum Step } \\
\text { Size }(\mu)\end{array}$ & Error \\
\hline $6 \mathrm{~cm}$ & Height & 0.000861 & 0.0014 \\
\hline $10 \mathrm{~cm}$ & Width & 0.00029615 & 0.0001 \\
\hline $12 \mathrm{~cm}$ & Height & 0.000208 & 0.0046 \\
\hline $20 \mathrm{~cm}$ & Length & 0.0000778 & 0.0074 \\
\hline $20 \mathrm{~cm}$ & Width & 0.00007328 & 0.0003 \\
\hline $40 \mathrm{~cm}$ & Length & 0.00002059 & 0.0063 \\
\hline
\end{tabular}

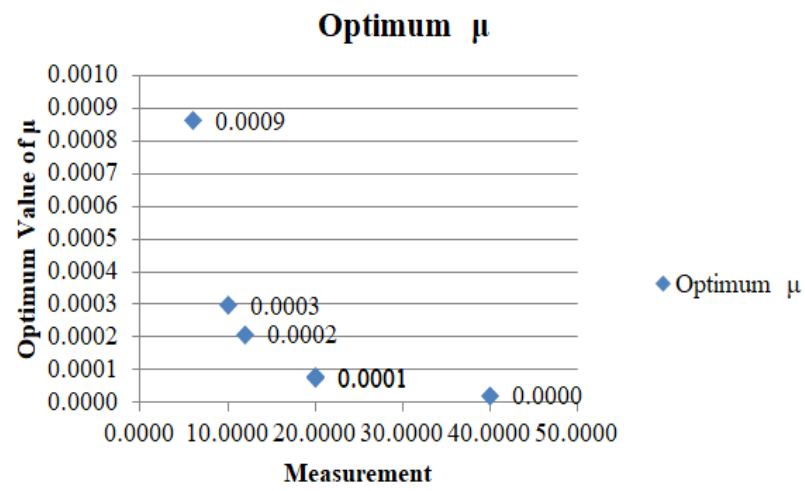

Figure. 30 The size of the object is inversely proportional to the parameter value $\mu$

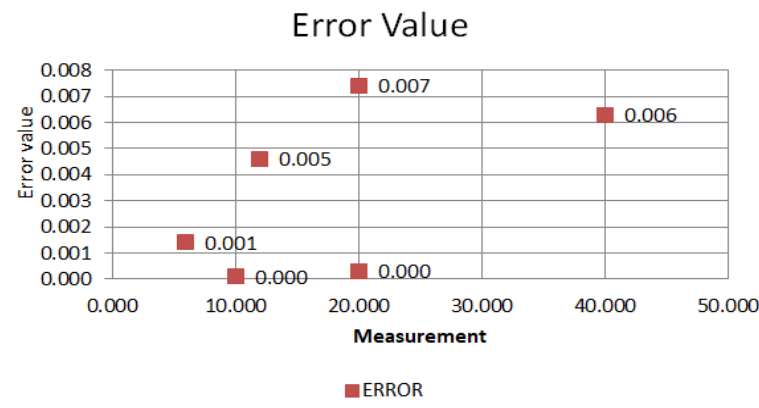

Figure. 31 Error prediction

Optimum step size and error is presented as a graphic in Fig. 30 and Fig. 31.

By conditioning the error, the predictive adaptive process would get a value close to accurate.

Fig. 31 shows the error value that could be conditioned to find the desired output.

\section{Scaling prototype and actual device}

Fig. 32 shows the size of the prototype compared to an artificial river and could be the basis for measuring the actual device when applied to a real river.

Fig. 33 shows the prototype with the dimension that could be the basis for measuring the actual device when applied to a real river.

To determine the size of the device for real conditions, it is necessary to calculate the surface area of the artificial river compared to the surface area of

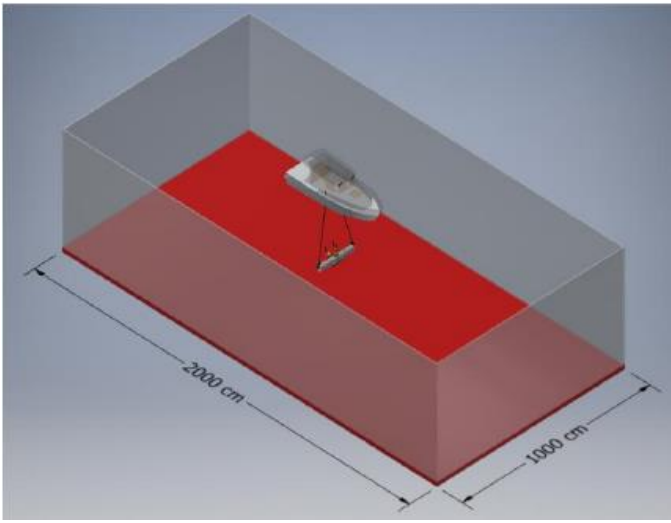

Figure. 32 Prototype and artificial river

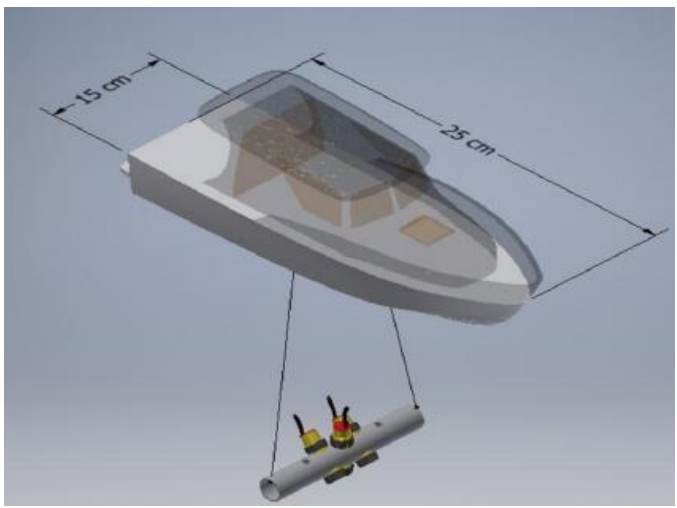

Figure. 33 Prototype with sensors

the real river. The calculation results showed the prototype was $(15 \mathrm{~cm} \times 25 \mathrm{~cm})=375 \mathrm{~cm} 2$, while the area of the artificial river to be checked was $(100 \mathrm{~cm}$ $x 200 \mathrm{~cm})=20.000 \mathrm{~cm} 2$.

The river was examined per section and the area of each section was $600 \mathrm{~m}^{2}$. Thus, when applying a real device in the real river, the size of the device does not have to be adjusted to the length of the river, only adjusted to a certain river area, i.e., $6.000 .000 \mathrm{~cm}^{2}$. The device would move every 10 meters to measure an area of $600 \mathrm{~m}^{2}$.

Thus, for a real river with area $600 \mathrm{~m}^{2}$, the device must have the surface area:

$$
\frac{(6.000 .000)(373)}{20.000}=112.500 \mathrm{~cm}^{2}
$$

and must be broken down in length and width.

From Fig. 33, the ratio between length and width is length: width $=l: w=5: 3$, so that, the dimension of the actual boat must be:

$$
\begin{aligned}
l x w & =112.500 \\
l & =\frac{112.500}{w} \\
\frac{l}{w} & =\frac{112.500 / w}{w}
\end{aligned}
$$




$$
l: w=5: 3
$$

From Eqs. (19) and (20):

$$
\begin{aligned}
& \frac{(112.500 / w)}{w}=5: 3 \\
& 3\left(\frac{112.500}{w}\right)=5 w
\end{aligned}
$$

So that,

$w=259.8 \mathrm{~cm} ; l=433.02 \mathrm{~cm}$

The device to be made had the dimensions $l=433.02$ $\mathrm{cm}$ and $w=259.8 \mathrm{~cm}$ or if rounded $l=433 \mathrm{~cm}$ and $w=260 \mathrm{~cm}$.

\section{Conclusion}

The front DC motor control process using FLC algorithms is better than a PID algorithm, because FLC converges in less than 4 seconds with an error rate 0.0005 and PID algorithm converges in more than 4 seconds with an error rate 0.001 .

Fuzzy intuitive Sets concluded that only "width" is the valid measurement. The others cannot be considered valid. So, it is necessary to carry out a predictive LMS Adaptive process to fix the errors occurred.

The predictive LMS adaptive algorithm will get a measurement value that is close to accurate value with the step size between 0,00002 and 0,0003 depend on the size of the object. The size of the object is inversely proportional to the step size $\mu$. The predictive LMS adaptive algorithm can minimize the error up to a one-thousandth level of accuracy.

After scaling between the prototype and the actual device, it is obtained that the dimension of actual device is close to $433 \mathrm{~cm}$ long and $260 \mathrm{~cm}$ wide.

The hybrid method between FLC, Fuzzy Intuitive and LMS can be used to measure the volume of river's sediment properly.

\section{References}

[1] Akbar Muhamad, "82 Persen Sungai di Indonesia Tercemar dan Kritis | Republika Online", 2019.

[2] Z. S. A. Rahman, "Design a Fuzzy Logic Controller for Controlling Position of D . C . Motor", Int. J. Comput. Eng. Res. Trends, Vol. 4, No. 7, pp. 285-289, 2017.

[3] R. Diamant, D. Kipnis, E. Bigal, A. Scheinin, D. Tchernov, and A. Pinchasi, "An Active Acoustic Track-Before-Detect Approach for Finding
Underwater Mobile Targets", IEEE J. Sel. Top.

Signal Process., Vol. 13, No. 1, pp. 104-119, 2019.

[4] A. Rodríguez-Molina, M. G. VillarrealCervantes, and M. Aldape-Pérez, "An adaptive control study for the DC motor using metaheuristic algorithms", Soft Comput., Vol. 23, No. 3, pp. 889-906, 2019.

[5] H. Ghafoor and Y. Noh, "An Overview of NextGeneration Underwater Target Detection and Tracking: An Integrated Underwater Architecture", IEEE Access, Vol. 7, pp. 9884198853, 2019.

[6] H. Hu, T. Wang, S. Zhao, and C. Wang, "Speed control of brushless direct current motor using a genetic algorithm-optimized fuzzy proportional integral differential controller", Adv. Mech. Eng., Vol. 11, No. 11, pp. 1-13, 2019.

[7] S. P. Sari, "Deteksi dan Interpretasi Target Di Dasar Laut Menggunakan Instrumen Side Scan Sonar", Seminar Nasional Teori dan Aplikasi Teknologi Kelautan, p. A-25-A-30.2009, 2009.

[8] J. Dalle, M. Z. Elfirman, and M. Sufyan, "Microcontroller based water measurement level prototype using fuzzy logic method", TEM J., Vol. 9, No. 2, pp. 694-701, 2020.

[9] S. Matteoli, G. Corsini, M. Diani, G. Cecchi, and G. Toci, "Automated Underwater Object Recognition by Means of Fluorescence LIDAR", IEEE Trans. Geosci. Remote Sens., Vol. 53, No. 1, pp. 375-393, 2015.

[10] V. Mitra, C. J. Wang, and S. Banerjee, "Lidar detection of underwater objects using a neuroSVM-based architecture", IEEE Trans. Neural Networks, Vol. 17, No. 3, pp. 717-731, 2006.

[11] A. Abu and R. Diamant, "A Statistically-Based Method for the Detection of Underwater Objects in Sonar Imagery", IEEE Sens. J., Vol. 19, No. 16, pp. 6858-6871, 2019.

[12] G. Bouchette, P. Church, J. E. McFee, and A. Adler, "Imaging of compact objects buried in underwater sediments using electrical impedance tomography", IEEE Trans. Geosci. Remote Sens., Vol. 52, No. 2, pp. 1407-1417, 2014.

[13] S. Jay, M. Guillaume, and J. Blanc-Talon, "Underwater target detection with hyperspectral data: Solutions for both known and unknown water quality", IEEE J. Sel. Top. Appl. Earth Obs. Remote Sens., Vol. 5, No. 4, pp. 1213-1221, 2012.

[14] Y. Zhang, M. A. Godin, J. G. Bellingham, and J. P. Ryan, "Using an autonomous underwater vehicle to track a coastal upwelling front", IEEE 
J. Ocean. Eng., Vol. 37, No. 3, pp. 338-347, 2012.

[15] O. Postolache, J. D. Pereira, and P. S. Girão, "Wireless sensor network-based solution for environmental monitoring: Water quality assessment case study", IET Sci. Meas. Technol., Vol. 8, No. 6, pp. 610-616, 2014.

[16] L. Jun, X. Shouyong, C. Chong, X. Dan, and Y. Mingiin, "A spintronic memristor crossbar array for fuzzy control with application in the water valves control system", Meas. Control (United Kingdom), Vol. 52, No. 5-6, pp. 418-431, 2019.

[17] T. Karlita, E. M. Yuniarno, I. K. E. Purnama, and M. H. Purnomo, "Design and Development of a Mechanical Linear Scanning Device for the Three-Dimensional Ultrasound Imaging System", Int. J. Electr. Eng. Informatics, Vol. 11, No. 2, pp. 272-295, 2019.

[18] J. Kulicka, "The fuzzy intuitive sets in the decision-making”, Int. J. Eng. Technol. Comput. Res., Vol. 3, No. 2, pp. 176-180, 2015.

[19] K. T. Atanassov, On intuitionistic fuzzy sets theory, Vol. 283. 2012.

[20] S. A. D. Prasetyowati, B. Arifin, and N. B. S. Eka, "Solution for Vehicles Noise Cancellation With Modification of LMS Adaptive Algorithm", Int. J. Comput. Sci. Eng. (IJCSE, Vol. 4, No. 5, pp. 929-937, 2012.

[21] S. A. D. Prasetyowati and A. Susanto, "Multiple processes for least mean square adaptive algorithm on roadway noise cancelling", Int. J. Electr. Comput. Eng., Vol. 5, No. 2, pp. 355-360, 2015.

[22] P. Sun and A. Boukerche, "Modeling and analysis of coverage degree and target detection for autonomous underwater vehicle-based system", IEEE Trans. Veh. Technol., Vol. 67, No. 10, pp. 9959-9971, 2018.

[23] A. Flores and B. Widrow, "Assesment of the efficiency of the LMS algorithm based on spectral information", In: Proc. of Conf. Rec. Asilomar Conf. Signals, Syst. Comput., Vol. 1, No. 1, pp. 120-124, 2004.

[24] S. Gazor, "Prediction in LMS-type adaptive algorithms for smoothly time varying environments", IEEE Trans. Signal Process., Vol. 47, No. 6, pp. 1735-1739, 1999.

[25] J. R. Zeidler, "Performance Analysis of LMS Adaptive Prediction Filters", In: Proc. of IEEE, Vol. 78, No. 12, pp. 1781-1806, 1990. 